\title{
O plano estratégico de Barcelona educadora
}

\author{
Ana Maria Wilheim*
}

\section{Das cinzas da ditadura para uma cidade do conhecimento}

Em 2004, passei seis meses em Barcelona, onde fui estudar Gestão de Cidades, suas políticas e programas. Barcelona é uma cidade que renasceu das cinzas de uma ditadura pesada de 40 anos, com muita morte e muita opressão. Opressão política, de identidade cultural, opressão da língua...

Na década de 1980, quando a democracia se instalou, as lideranças socialistas que assumiram a gestão da cidade começaram a reintegrá-la e a recompor o sentido da cidadania. Aporta-se, para as discussões de governo, toda a experiência de trabalho de base nos bairros e associações de moradores, que foram espaços de resistência e onde havia muito conhecimento acumulado sobre a realidade local, com forte posicionamento ideológico e desejo de reconstrução.

A base de uma Cidade Educadora nasceu, desde então, com muita participação popular, das associações de moradores, que se organizam, pautam seus problemas, se capacitam e negociam com a administração pública. Hoje, se comparamos com a nossa realidade, podemos dizer que Barcelona tem políticas públicas descentralizadas, integradas e participativas. As políticas urbanas e sociais, a educação e a cultura, integradas, dialogam com um plano estratégico que busca alcançar um objetivo urbano: ser uma cidade do conhecimento.

As bases da Cidade Educadora se apóiam na crença de que a cidade é um espaço educador. E, para que o exercício da cidadania ocorra, o indivíduo necessita de

\footnotetext{
* Ana Maria Wilheim é socióloga, consultora especializada em advocacy, mobilização e comunicação no terceiro setor. Foi superintendente e assessora da presidência da Fundação Abrinq pelos Direitos da Criança e membro do Conselho Diretor do Grupo de Institutos, Fundações e Empresas (Gife).
}

informação e de meios para participar da construção desse espaço coletivo, para que ele seja de fato um espaço público, um espaço com memória e história, conhecida e reconhecida por seus atores. Um território com dimensões humanas, desenhado para ser ocupado por seus cidadãos. Um espaço físico com dimensões e funções que permitem ao usuário sentir-se parte dele e responsável por ele. Por isso, a intervenção urbana e as obras físicas têm que dialogar com as ações e intervenções sociais e culturais.

Um dos maiores e primeiros investimentos feitos em Barcelona, nos anos 1980, foi a criação e disseminação de uma rede de bibliotecas e centros cívicos e culturais nos bairros. 0 intuito era o de investir em informação e em campanhas educativas e cívicas como um meio pedagógico de se trabalhar a educação de massa para todos, o tempo todo. Para isso, as diretrizes e ações no campo da cultura e da educação caminham juntas e interagem com as políticas econômicas. Com uma boa programação cultural, uma boa comunicação de massa e tendo como base os valores humanos e de cidadania, a cidade pode receber visitantes, turistas, que aquecem a economia e projetam também a cidade no exterior.

Todos ganham com isso, pois essa articulação foi pensada e negociada num longo e vasto trabalho de planejamento estratégico, em que participaram os diversos atores sociais: políticos, organizações do terceiro setor, empresários e trabalhadores.

O plano estratégico de Barcelona e região metropolitana constituiu-se em um processo de mobilização que hoje, além de processo, é uma entidade que cuida especificamente de fazer valer e monitorar o seu desempenho. 0 mais interessante é que se reconhecem, nas equipes da administração pública, nas organizações comerciais e nos sindicatos de trabalhadores, a presença das diretrizes e o norteamento definido no plano estratégico. 
Outro importante investimento no plano das obras físicas e urbanas foi a construção de meios e vias de acesso, ou seja, conectividade com os bairros mais isolados, como conjuntos habitacionais populares de trabalhadores, construídos nos anos duros da ditadura, isolados dos centros urbanos e dos serviços públicos, panorama este muito conhecido por nós, brasileiros e paulistanos.

Se acreditarmos que os processos de formação do indivíduo ocorrem sob a influência do seu meio, da família e da escola, devemos dar mais importância para os efeitos da comunicação e do relacionamento que a cidade estabelece com seus diversos usuários, a começar pelas crianças.

Uma cidade que se comunica de forma pedagógica com suas crianças certamente se comunica bem com a maioria da população. 0 aluno que freqüenta a escola está inserido numa cidade, num bairro, num determinado contexto histórico e socioeconômico que influenciam seu modo de pensar e de se relacionar com a comunidade. Valorizar esses elementos externos no processo de formação e aprendizagem das novas gerações nos parece de extrema importância.

Levar educação, cultura e esporte para as áreas distantes dos centros urbanos e fazer a conexão dessas áreas com os centros urbanos, dando à população acesso aos circuitos dos museus e aos circuitos da cultura, é parte fundamental da agenda de uma cidade educadora.

\section{Compartilhar projetos comuns}

\section{Extrato da entrevista da Secretária Geral da} Associação Internacional das Cidades Educadoras, Sra. Pilar Filgueras Bellot, de Barcelona, Espanha, concedida a Og Roberto Dória e Ana Maria Wilheim.

Em Barcelona, o processo de transição de uma Cidade Educativa para uma Cidade Educadora começou no momento em que Barcelona era candidata às Olimpíadas. 0 então prefeito Pascal Maragall tinha a intenção de apresentar Barcelona como a cidade candidata e de uma forma bastante profunda e consistente.

Ele pretendia utilizar essa candidatura como uma oportunidade para que a cidade desse um passo à frente em muitos setores, de modo bastante articulado, tanto no urbanístico, quanto no social, cultural e esportivo. Maragall queria que a organização dos jogos fosse uma oportunidade para desencadear um grande processo de transformação em termos de gestão e de política urbana e também de envolvimento dos cidadãos em todo o processo. Eu acredito que realmente os jogos olímpicos foram uma amostra desta coesão da cidadania com um projeto comum.

Essa coesão se traduziu em comportamentos variados; por exemplo, a apropriação por parte dos cidadãos dos novos espaços públicos que se foram construindo na cidade. É importante dizer que houve muita preocupação no sentido de dar dignidade aos bairros mais desfavorecidos e conectar bairros que, até então, estavam separados por vias de trens ou por fábricas. Houve uma transformação radical e isso teve como conseqüência uma mudança de atitude em termos gerais.

Os cidadãos se apropriavam das novas propostas de forma patente e se sentiam muito satisfeitos com a evolução da cidade. Compreendiam tanto o que estava acontecendo que foram capazes de agüentar meses de obras pesadas, porque sabiam que isso os conduziria a uma situação melhor.

0 mesmo sucedeu com o esporte. Deram muita atenção à questão de formação de jovens, proporcionando esporte aos distritos e construindo ginásios esportivos, ou seja, havia uma ação sinérgica que conduzia todos em direção a um projeto global. Então, nesse marco, o prefeito também teve vontade de conectar tudo isso com a educação, visando à formação da cidadania. Portanto, as condições para a constituição da Cidade Educadora estavam dadas e eram bastante favoráveis.

Eu tinha lido coisas sobre Cidade Educativa já em uma obra editada, em 1972, pela Unesco, que se intitulava Aprender a ser. Apesar de o livro ser centrado na educação formal, havia o capítulo "Cidade Educativa", que era muito sugestivo e abria realmente outro horizonte.

Sabe como é quando se tem a convicção de que as coisas tendem por esse caminho? 


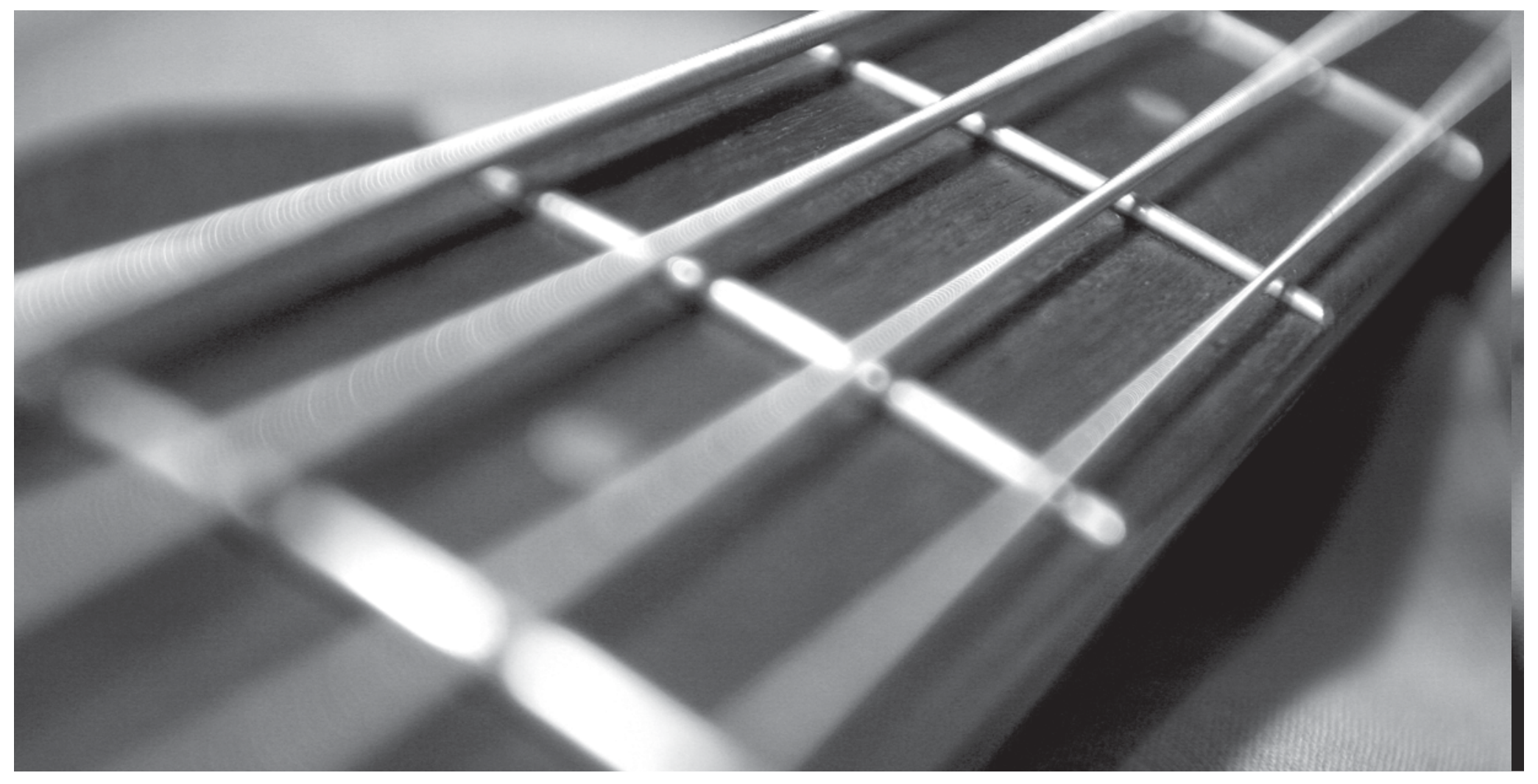

